\title{
Hydrocortisone malabsorption due to polyethylene glycols (Macrogol 3350) in a girl with congenital adrenal insufficiency
}

\author{
Stefano Stagi, Paolo Del Greco, Franco Ricci, Chiara lurato, Giovanni Poggi, Salvatore Seminara
}

and Maurizio de Martino

\begin{abstract}
Background: Primary adrenal insufficiency is relatively rare in children and, if unrecognized, may present with cardiovascular collapse, making it a potentially life-threatening entity.

Case presentation: The proposita, 11 months old of age, was admitted for lethargy and severe dehydration. Blood pressure was $62 / 38 \mathrm{~mm} \mathrm{Hg}$, and biochemical measurements showed hyponatraemia, hypochloraemia, hyperkalaemia, and metabolic acidaemia. Renin activity was $1484 \mu \mathrm{U} / \mathrm{mL}$; cortisol, $1.03 \mu \mathrm{g} / \mathrm{dL}$ (normal, $5-25 \mu \mathrm{g} / \mathrm{dL}$ ); and corticotropin (ACTH), $4832 \mathrm{ng} / \mathrm{L}$ (normal, 9-52 ng/L). Adrenal deficiency was diagnosed, and replacement therapy with glucocorticoids and mineralocorticoids was initiated. After 40 days, ACTH was $797 \mathrm{ng} / \mathrm{L}$.

During follow-up, the patient started taking macrogol twice daily for constipation and experienced a significant increase in ACTH (3262 ng/L), which dropped to $648 \mathrm{ng} / \mathrm{L}$ when macrogol was stopped. After arbitrary reintroduction of macrogol, the child presented with hypoglycaemia, lethargy, weakness, and hypotonia; ACTH was $3145 \mathrm{ng} / \mathrm{L}$. After again stopping macrogol, her ACTH was near normalized (323 ng/L).
\end{abstract}

Conclusion: Hydrocortisone malabsorption may be caused by macrogol use. Because chronic constipation is frequently reported in children, the possibility that macrogol contributes to adrenal crisis should be taken in account.

Keywords: Macrogol, Hydrocortisone, Adrenal insufficiency, Malabsorption, Polyethylene glycol, Constipation

\section{Introduction}

Adrenal insufficiency is relatively rare in children and may be categorized as primary or secondary and congenital or acquired [1]. Primary adrenal insufficiency can be caused by a deficiency in steroid biosynthesis or abnormal adrenal gland development. It is a life-threatening disorder that can result from primary adrenal failure or secondary adrenal disease resulting in impairment of the hypothalamicpituitary axis. Prompt diagnosis and urgent mineralocorticoid and glucocorticoid replacement is mandatory [2]; however, correct management is also essential [3].

Chronic idiopathic constipation is frequently reported and reduces patient quality of life $[4,5]$. In fact, chronic constipation is associated with long-term problems including megarectum, reduced sensitivity of the rectum

\footnotetext{
* Correspondence: stefano.stagi@yahoo.it

Department of Health Sciences, University of Florence, Anna Meyer Children's University Hospital, Florence, Italy
}

to the presence of faeces, and abnormal gut motility [4]. In many children, constipation is triggered by painful bowel movements caused by factors such as toilet training, changes in routine or diet, stressful events, intercurrent illness, or delaying defecation [4]. Therefore, managing chronic constipation in children effectively and early in its course is important in preventing long-term defecation disorders [4].

Polyethylene glycols (PEGs, or macrogols) are hydrophilic polymers of ethylene oxide [6] used in many drugs such as bowel preparations, dispersing agents, and excipients, and in cosmetics [7]. Water makes up 75-80\% (wt/wt) of the normal stool, and a difference of only $10 \%$ in hydration results in marked changes in stool consistency [8]. Because PEG is a large molecular weight water-soluble polymer, it has the capacity to form hydrogen bonds with 100 molecules of water per molecule of PEG [9]. When PEG is administered orally, the resulting hydration of the 
colonic content facilitates transit and painless defecation in a linear dose-dependent fashion [10]. Therefore, PEGbased laxatives, when used in escalating doses, can also be used to completely remove faecal loading in preference to rectally-administered treatments. Standard management of chronic constipation tends to begin with correction of dietary and lifestyle factors that predispose to the condition and focus on increasing dietary fibre and fluid intake [11]. Dietary manipulation alone, including the use of corn syrup, was successful in resolving all symptoms of constipation in $25 \%$ of children aged up to 2 years in one US study [5].

We describe a girl with adrenal insufficiency managed with hydrocortisone and fluorocortisone who showed an adrenal crisis after administration of macrogol 3350, and we discuss this aspect, focusing on the aetiology of adrenal insufficiency in childhood.

\section{Case report}

The proposita, 11 months old of age, was admitted to Anna Meyer Children's University Hospital for lethargy and severe dehydration without history of vomiting or diarrhoea. She was the first child of non-consanguineous, young, healthy Italian parents, born at term (39 wks of gestation) by natural childbirth. Birth weight was $3200 \mathrm{~g}$ (0.12 standard deviation score $[\mathrm{SDS}], 50^{\text {th }}-75^{\text {th }}$ centile), length, $51 \mathrm{~cm}$ (1.12 SDS, $75^{\text {th }}-90^{\text {th }}$ centile), and head circumference, $35 \mathrm{~cm}$ (1.04 SDS, $75^{\text {th }}-90^{\text {th }}$ centile). There were no perinatal problems or familial history of similar presentations or features of endocrine disease. Neuromotor development was normal; she was sitting at 5 months.

At 10 months, 20 days of age, she started showing weight loss, lethargy, weakness, hypotonia, and dark skin. She was mildly dehydrated. Her body weight, length, and head circumference were $10.850 \mathrm{~kg}$ (1.89 SDS, $97^{\text {th }}$ centile), $73 \mathrm{~cm}$ (0.61 SDS, $50^{\text {th }}-75^{\text {th }}$ centile), and $46.5 \mathrm{~cm}$ (1.30 SDS, $90^{\text {th }}$ centile), respectively. There were no dysmorphic features. External genitalia were normal female type with no ambiguity. There was no abdominal or inguinal mass discovered upon abdominal examination. Blood pressure was 62/38 mm $\mathrm{Hg}$; respiration, 35/min; pulse, $121 / \mathrm{min}$; and body temperature, $37.3^{\circ} \mathrm{C}$.

Biochemical measurements indicated hyponatraemia $(\mathrm{Na}, 125 \mathrm{mEq} / \mathrm{L})$, hypochloraemia $(\mathrm{Cl}, 86 \mathrm{mEq} / \mathrm{L})$, hyperkalaemia (K, $5.7 \mathrm{mEq} / \mathrm{L})$, metabolic acidaemia by arterial venous blood gas, elevated serum urea nitrogen $(60 \mathrm{mg} / \mathrm{dL})$, and normal creatinine $(0.3 \mathrm{mg} / \mathrm{dL})$. Glucose was $56 \mathrm{mg} / \mathrm{dL}$ (normal, 55-110 mg/dL). An extensive endocrine workup, carried out at $8 \mathrm{AM}$ after an overnight fast, showed free thyroxin was $1.27 \mathrm{ng} / \mathrm{dL}$ (normal, 0.80-1.90 ng/dL); thyrotropin, $3.96 \mu \mathrm{IU} / \mathrm{dL}$ (normal, 0.4-4.0 $\mu \mathrm{IU} / \mathrm{dL}$ ); aldosterone, $0.19 \mathrm{nmol} / \mathrm{L}$ (normal, $0.96-8.31 \mathrm{nmol} / \mathrm{L}$ ); renin activity, $1484 \mu \mathrm{U} / \mathrm{mL}$ per h (normal, 2-10.2 $\mu \mathrm{U} / \mathrm{mL}$ per $\mathrm{h}$ ); 17 $\mathrm{OH}$-progesterone, $<0.5 \mathrm{nmol} / \mathrm{L}$; dehydroepiandrosterone sulfate, < $15 \mu \mathrm{g} / \mathrm{dL}$; cortisol, $1.03 \mu \mathrm{g} / \mathrm{dL}$ (normal, 5-25 $\mu \mathrm{g}$ / dL); ACTH, 4832 ng/L (normal, 9-52 ng/L; Figure 1), luteinizing hormone, $2.3 \mathrm{IU} / \mathrm{L}$; and follicle stimulating hormone, $5.6 \mathrm{IU} / \mathrm{L}$.

Serum cortisol and plasma ACTH levels were measured routinely using an Immulite 2000 chemiluminescence immunometric assay (Diagnostic Products Corporation, xLos Angeles, CA, USA). The cortisol inter-assay and intra-assay coefficients of variation were $<9.5 \%$ and $7.4 \%$, respectively. The ACTH inter-assay and intra-assay coefficients of variation ranged from $6.1 \%$ to $10.0 \%$ and from $6.7 \%$ to $9.5 \%$, respectively.

The patient was hydrated with normal saline and required vasopressors. Adrenal deficiency was diagnosed considering the hyponatraemia, hyperkalaemia, metabolic acidaemia, and cortisol and corticotropin levels.

The usual causes of primary adrenal insufficiency were ruled out (Table 1). Family history was negative for autoimmune diseases and endocrinological or genetic syndromes. Renal Doppler ultrasonography was performed and was normal. Autoimmune Addison, in the context of autoimmune polyendocrinopathy candidiasis ectodermal dystrophy (APECED) or other autoimmune syndromes was ruled out by clinical and biochemical evaluation. Mantoux was negative and Veneral Disease Research Laboratory (VDRL) was non-reactive. Human immunodeficiency virus was seronegative. Plasma levels of very long chain fatty acids (VLCFAs) were normal. We performed a synthetic ACTH stimulation test intravenously at $8 \mathrm{AM}$ after an overnight fast, and the cortisol response, measured at 0,30 , and 60 minutes after infusion was blunted $(0.98,1.39$, and $2.01 \mu \mathrm{g} / \mathrm{dL}$, respectively). An MRI scan of the bilateral adrenal glands revealed agenesis of the right and hypoplasia of the left adrenal glands (Figures 1A and B).

Replacement therapy with standard doses of glucocorticoid (hydrocortisone, $15 \mathrm{mg} / \mathrm{m}^{2} /$ day), mineralocorticoid (fluorocortisone, $0.2 \mathrm{mg} /$ day), and sodium chloride $(\mathrm{NaCl}, 1 \mathrm{~g} /$ day) was initiated.

Routine cytogenetic investigations revealed an apparently normal female karyotype (46, XX). Molecular karyotyping was performed using an array comparative genomic hybridization analysis using proband's DNA and a $44 \mathrm{~K}$ array platform (Agilent Technologies) with a resolution of approximately 100 kilobase. This examination yielded normal results.

After replacement therapy, electrolyte abnormalities were corrected during the first week, and the patient was discharged in good clinical condition. During follow-up, she maintained good condition, good appetite, weight gain, and normal laboratory results with reduced ACTH (Figure 2). After 10 days, ACTH was $3214 \mathrm{ng} / \mathrm{L}$; renin activity, $165.3 \mu \mathrm{U} / \mathrm{mL} ; \mathrm{Na}, 139 \mathrm{mEq} / \mathrm{L} ; \mathrm{K}, 4.4 \mathrm{mEq} / \mathrm{L}$; and Cl, $96 \mathrm{mEq} / \mathrm{L}$, and after 40 days ACTH was $797 \mathrm{ng} / \mathrm{L}$. 

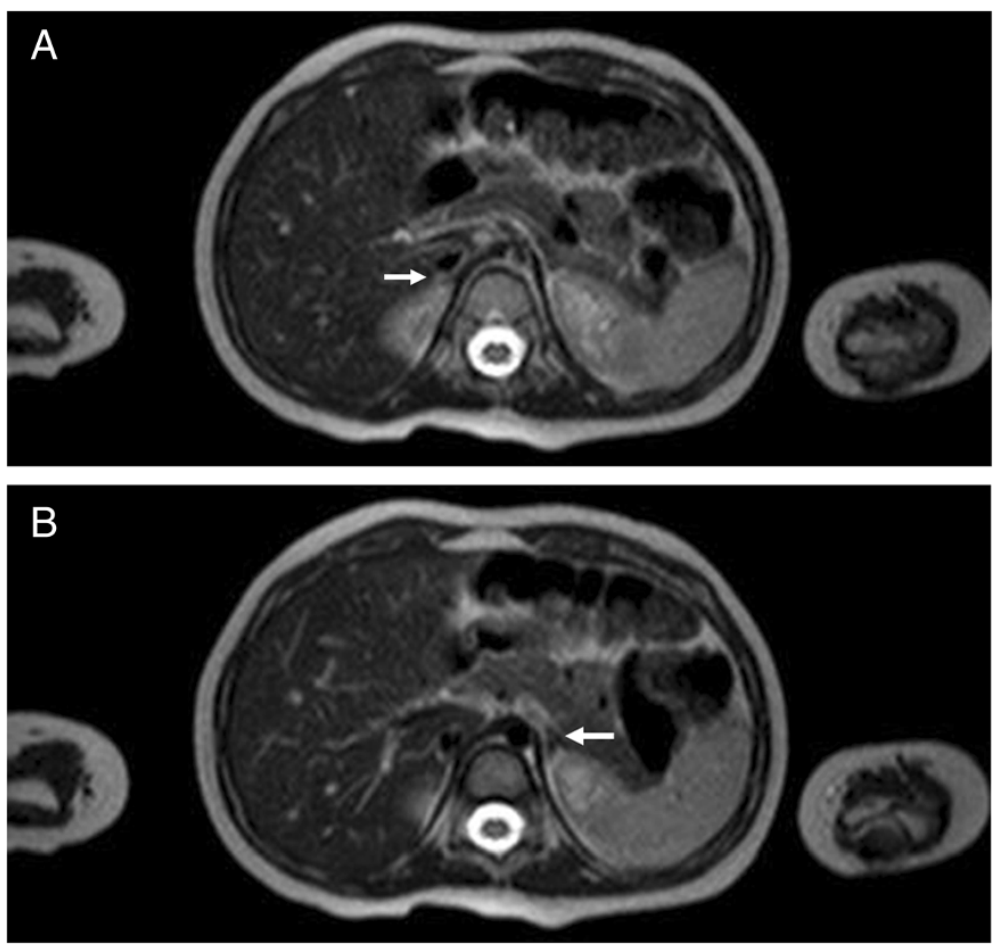

Figure $1 \mathrm{MRI}$ scan of the bilateral adrenal glands revealing agenesis of the right (A) and hypoplasia of the left (B) adrenal glands.

At 14 months of age, the patient started taking macrogol twice daily for constipation, about 30 to 60 minutes after taking hydrocortisone and fluorocortisone. Testing revealed that $\mathrm{ACTH}$ was $300 \mathrm{ng} / \mathrm{L}$, and renin activity was $24.2 \mu \mathrm{U} / \mathrm{mL}$. Analysis of the $S F 1$ gene was normal with the exception of a c.437G $>C$ polymorphism.

After 3 months of macrogol therapy, Na was $135 \mathrm{mEq} / \mathrm{L}$; $\mathrm{Cl}, 106 \mathrm{mEq} / \mathrm{L}$; K, $5.3 \mathrm{mEq} / \mathrm{L}$; renin activity, $124.2 \mu \mathrm{U} / \mathrm{mL}$; aldosterone, $0.13 \mathrm{nmol} / \mathrm{L}$; cortisol, $1.78 \mu \mathrm{g} / \mathrm{dL}$; and ACTH, $3262 \mathrm{ng} / \mathrm{L}$. The macrogol was stopped, resulting in a rapid reduction of corticotropin; after 28 days it was $648 \mathrm{ng} / \mathrm{L}$. At this time, faecal elastase was $548 \mu \mathrm{g} / \mathrm{g}$ (normal, > $200 \mu \mathrm{g} / \mathrm{g}$ ), and steatocrit was $0 \%$ (normal, <3\%). Screening for celiac disease was negative (IgA, $38 \mathrm{mg} / \mathrm{dL}$; tTG, $1.0 \mathrm{U} / \mathrm{mL})$.

Unfortunately, the family arbitrarily reintroduced macrogol (once daily, more than 2 hours after taking hydrocortisone and fluorocortisone) for chronic constipation. After 1 month, during a respiratory tract infection, the child presented with hypoglycaemia, lethargy, weakness, and hypotonia. Vitals were measured: pulse, 134/min; blood pressure, 65/42 $\mathrm{mm} \mathrm{Hg}$; and respiration, 38/min. Glucose was $36 \mathrm{mg} / \mathrm{dL}$; Na, $132 \mathrm{nEq} / \mathrm{L} ; \mathrm{Cl}, 92 \mathrm{mEq} / \mathrm{L} ; \mathrm{K}, 5.4 \mathrm{mEq} / \mathrm{L}$; and ACTH, $3145 \mathrm{ng} / \mathrm{L}$. During recovery, we treated the adrenal deficiency and stopped the macrogol with near normalization of corticotropin (323 ng/L) after 23 days (Figure 2). Neuro-metabolic tests (plasma aminoacidogram, urine aminoacidogram, acylcarnitine profile analysis, and redox state) were again normal.

\section{Discussion}

A variety of laxatives are available for treating constipation: bulk forming, osmotic, and stimulant laxatives. Osmotic laxatives, particularly PEG preparations, are popular because they are relatively safe, inexpensive, and better than lactulose in improving stool frequency and consistency [12-14]. Hydrocortisone is a hydrophilic drug used to treat many conditions, such as primary or secondary adrenal insufficiency, hypopituitarism, and adrenogenital syndrome.

Nevertheless, treatment of children suffering from adrenal insufficiency is frequently problematic for a number of reasons. For example, it requires use of pharmaceutical formulations that do not fully address the pharmacokinetic and pharmacodynamic problems of dosing infants. Therefore, children require careful monitoring of dose and dosage regimen. In fact, patients with adrenal insufficiency continue to have increased mortality and morbidity despite treatment and monitoring [15]. However, many drugs, for example, anticonvulsants such as phenytoin, phenobarbital, and carbamazepine, stimulate cytochrome P450 3A4, induce hepatic enzymes, and lead to accelerated glucocorticoid metabolism and reduced glucocorticoid effect, possibly causing acute adrenal insufficiency [16]. 
Table 1 Typical causes of primary adrenal insufficiency

\begin{tabular}{|c|c|c|c|}
\hline 1) Genetic disorders & $\begin{array}{l}\text { OMIM }^{1} \\
\text { (gene map) }\end{array}$ & Etiologic mechanisms & Other signs and symptoms \\
\hline Adrenoleukodystrophy & $300100($ Xq28) & Mutations of $A B C D 1^{2}, A B C D 2^{3}$ & $\begin{array}{l}\text { Weakness, diminished visual acuity, deafness, } \\
\text { cerebellar ataxia, hemiplegia, convulsions, dementia }\end{array}$ \\
\hline \multicolumn{4}{|l|}{$\begin{array}{l}\text { Congenital adrenal } \\
\text { hyperplasia }\end{array}$} \\
\hline 21-hydroxylase deficiency & $201910(6 p 21.33)$ & Mutations of $C Y P 21 A 2^{4}$ & Hyperandrogenism, ambiguous genitalia in females \\
\hline $\begin{array}{l}11 \beta \text {-hydroxylase } \\
\text { deficiency }\end{array}$ & $202010(8 q 24.3)$ & Mutations of $C Y P 11 B 1^{5}$ & Hyperandrogenism, hypertension \\
\hline $\begin{array}{l}\text { 33-hydroxysteroid } \\
\text { dehydrogenase } \\
\text { type } 2 \text { deficiency }\end{array}$ & $201810(1 \mathrm{p} 12)$ & Mutations of $\mathrm{HSD}_{3} B 2^{6}$ & Ambiguous genitalia in boys, postnatal virilisation in girls \\
\hline $\begin{array}{l}\text { 17a-hydroxylase } \\
\text { deficiency }\end{array}$ & 202110 (10q24.32) & Mutations of CYP17A1 ${ }^{7}$ & $\begin{array}{l}\text { Pubertal delay in both sexes, primary amenorrhea, } \\
\text { lack of secondary sexual characteristics, hypertension }\end{array}$ \\
\hline $\begin{array}{l}\text { P450 oxidoreductase } \\
\text { deficiency }\end{array}$ & $201750(7 q 11.23)$ & Mutations of $P O R^{8}$ & $\begin{array}{l}\text { Skeletal malformations, especially craniofacial; } \\
\text { severe abnormal genitalia }\end{array}$ \\
\hline $\begin{array}{l}\text { P450 side-chain cleavage } \\
\text { deficiency }\end{array}$ & $613743(15 q 24.1)$ & Mutations of $C Y P 11 A 1^{9}$ & $X Y$ sex reversal \\
\hline $\begin{array}{l}\text { Congenital lipoid adrenal } \\
\text { hyperplasia }\end{array}$ & $201710(8 p 11.23)$ & Mutations of STAR ${ }^{10}$ & $X Y$ sex reversal \\
\hline Smith-Lemli-Opitz syndrome & $270400(11 q 13.4)$ & Mutations of $D H C R 7^{11}$ & $\begin{array}{l}\text { Mental retardation, craniofacial malformations, } \\
\text { growth failure, cholesterol deficiency }\end{array}$ \\
\hline \multicolumn{4}{|l|}{$\begin{array}{l}\text { Adrenal hypoplasia } \\
\text { congenita }\end{array}$} \\
\hline X-linked & $300200($ Xp21.2) & Mutations of $N R O B 1^{12}$ & $\begin{array}{l}\text { Hypogonadotropic hypogonadism in boys (occasionally } \\
\text { in carrier females for skewed X-chromosome inactivation) }\end{array}$ \\
\hline Xp21 deletion syndrome & $300679(X p 21)$ & $\begin{array}{l}\text { Deletion of } G K^{13}, D M D^{14} \text {, } \\
\text { and } N R O B 1\end{array}$ & $\begin{array}{l}\text { Duchenne muscular dystrophy, glycerol kinase } \\
\text { deficiency psychomotor retardation }\end{array}$ \\
\hline SF1-linked & $612965(9 q 33.3)$ & Mutations of $N R 5 A 1^{15}$ & XY sex reversal \\
\hline IMAGe syndrome & $614732(11 \mathrm{p} 15.4)$ & Mutations of $C D K N 1 C^{16}$ & $\begin{array}{l}\text { Intrauterine growth retardation, metaphyseal dysplasia, } \\
\text { genital abnormalities }\end{array}$ \\
\hline Kearns-Sayre syndrome & & Deletions of mitochondrial DNA & $\begin{array}{l}\text { Deafness; heart, ocular and cerebral involvement; skeletal } \\
\text { muscle myopathy; intestinal disorders; hormonal deficits }\end{array}$ \\
\hline Wolman disease & 278000 (10q23.31) & Mutations of LIPA ${ }^{17}$ & Bilateral adrenal calcification, hepatosplenomegaly \\
\hline Sitosterolaemia & & $\begin{array}{l}\text { Mutations of } A B C G 5^{18} \\
\text { and } A B C G 8^{19}\end{array}$ & $\begin{array}{l}\text { Xanthomata, arthritis, premature coronary artery } \\
\text { disease, short stature, gonadal failure }\end{array}$ \\
\hline
\end{tabular}

Familial glucocorticoid deficiency or corticotropin insensitivity syndromes

$\begin{array}{lcl}\text { Type } 1 & 202200(18 p 11.21) & \text { Mutations of } M C 2 R^{20} \\ \text { Type } 2 & 607398(21 q 22.11) & \text { Mutations of MRAP } 21 \\ & 609981(8 q 11.21) & \text { Mutations of } M C M 4^{22} \\ \begin{array}{l}\text { Variant of familial } \\ \text { glucocorticoid deficiency }\end{array} & & \\ \text { Primary generalised } & (5 q 31.3) & \text { Mutations of } G C C R^{23} \\ \text { glucocorticoid resistance } & & \\ \begin{array}{l}\text { Triple A syndrome } \\ \text { (Allgrove's syndrome) }\end{array} & 231550(12 q 13.13) & \text { Mutations of } A A A S^{24}\end{array}$

Hyperpigmentation, tall stature, typical facial features, lethargy and muscle weakness with normal blood pressure Hyperpigmentation, normal height, hypoglycaemia, lethargy, and muscle weakness with normal blood pressure Growth failure, increased chromosomal breakage, natural killer cell deficiency

Fatigue, hypoglycaemia, hypertension, hyperandrogenism

Achalasia, alacrima, deafness, mental retardation, hyperkeratosis

\section{2) Acquired diseases}

$\begin{array}{lll}\begin{array}{l}\text { Bilateral adrenal } \\ \text { haemorrhage }\end{array} & - & \text { Meningococcal sepsis, } \\ \text { Bilateral adrenal metastases } & & \text { antiphospholipid syndrome } \\ & \text { Lung, stomach, breast, and } \\ \text { colon cancers }\end{array}$

Symptoms and signs of underlying disease

Disease-associated clinical manifestations 


\section{Table 1 Typical causes of primary adrenal insufficiency (Continued)}

\begin{tabular}{|c|c|c|c|}
\hline Bilateral adrenalectomy & - & $\begin{array}{l}\text { Adrenal masses, phaeochromocytoma } \\
\text { unresolved Cushing's syndrome }\end{array}$ & Symptoms and signs of underlying disease \\
\hline Bilateral adrenal infiltration & - & $\begin{array}{l}\text { Adrenal lymphoma, amyloidosis, } \\
\text { haemochromatosis }\end{array}$ & Disease-associated clinical manifestations \\
\hline $\begin{array}{l}\text { Drug-induced adrenal } \\
\text { insufficiency }\end{array}$ & - & $\begin{array}{l}\text { Anticoagulants, ketoconazole, } \\
\text { fluconazole, etomidate, } \\
\text { phenobarbital, phenytoin, } \\
\text { rifampicin, troglitazone }\end{array}$ & None, unless related to drug \\
\hline Infectious adrenalitis & - & $\begin{array}{l}\text { Tuberculosis, HIV-1, histoplasmosis, } \\
\text { cryptococcosis, coccidioidomycosis, } \\
\text { syphilis, trypanosomiasis }\end{array}$ & Disease-associated manifestations in other organs \\
\hline Autoimmune adrenalitis & - & & \\
\hline Isolated & & & None \\
\hline APS type 1 (APECED) & $240300(21 q 22.3)$ & Mutations of $A I R E^{25}$ & $\begin{array}{l}\text { Chronic mucocutaneous candidosis, } \\
\text { hypoparathyroidism, other autoimmune diseases }\end{array}$ \\
\hline APS type 2 & 269200 & & $\begin{array}{l}\text { Thyroid autoimmune disease, type } 1 \text { diabetes, } \\
\text { other autoimmune diseases }\end{array}$ \\
\hline APS type 4 & & & $\begin{array}{l}\text { Autoimmune gastritis, vitiligo, coeliac disease, alopecia, } \\
\text { excluding thyroid disease and type } 1 \text { diabetes }\end{array}$ \\
\hline \multicolumn{4}{|c|}{ 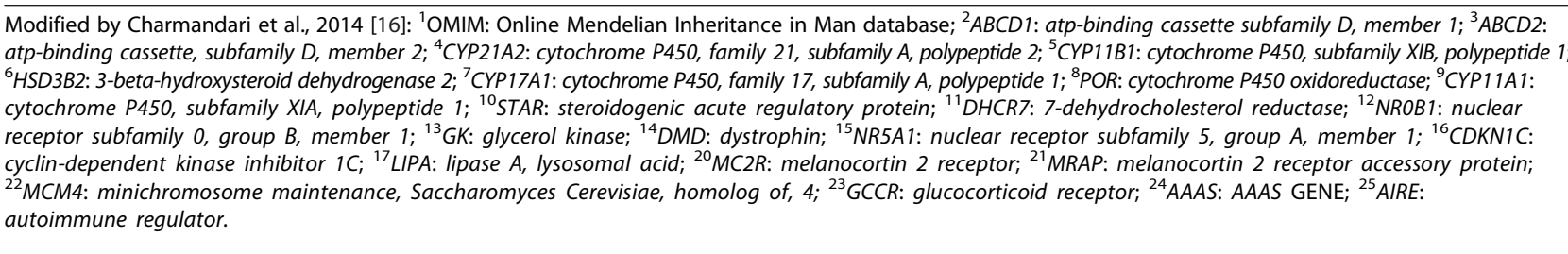 } \\
\hline
\end{tabular}

Hydrocortisone preparations are commonly combined with pharmaceutically acceptable carriers, typically inert, to facilitate their administration. Polyethylene glycol contains a mixture of inert water-soluble molecules of different sizes, whose absorption is independent of dosage, displaying decreasing mucosal transport with increasing molecular size. Macrogol solutions are commonly used for their efficacy and low rate of absorption $(0.2 \%)$ after oral administration [17] and typically have a safe profile with minimal reported side effects.

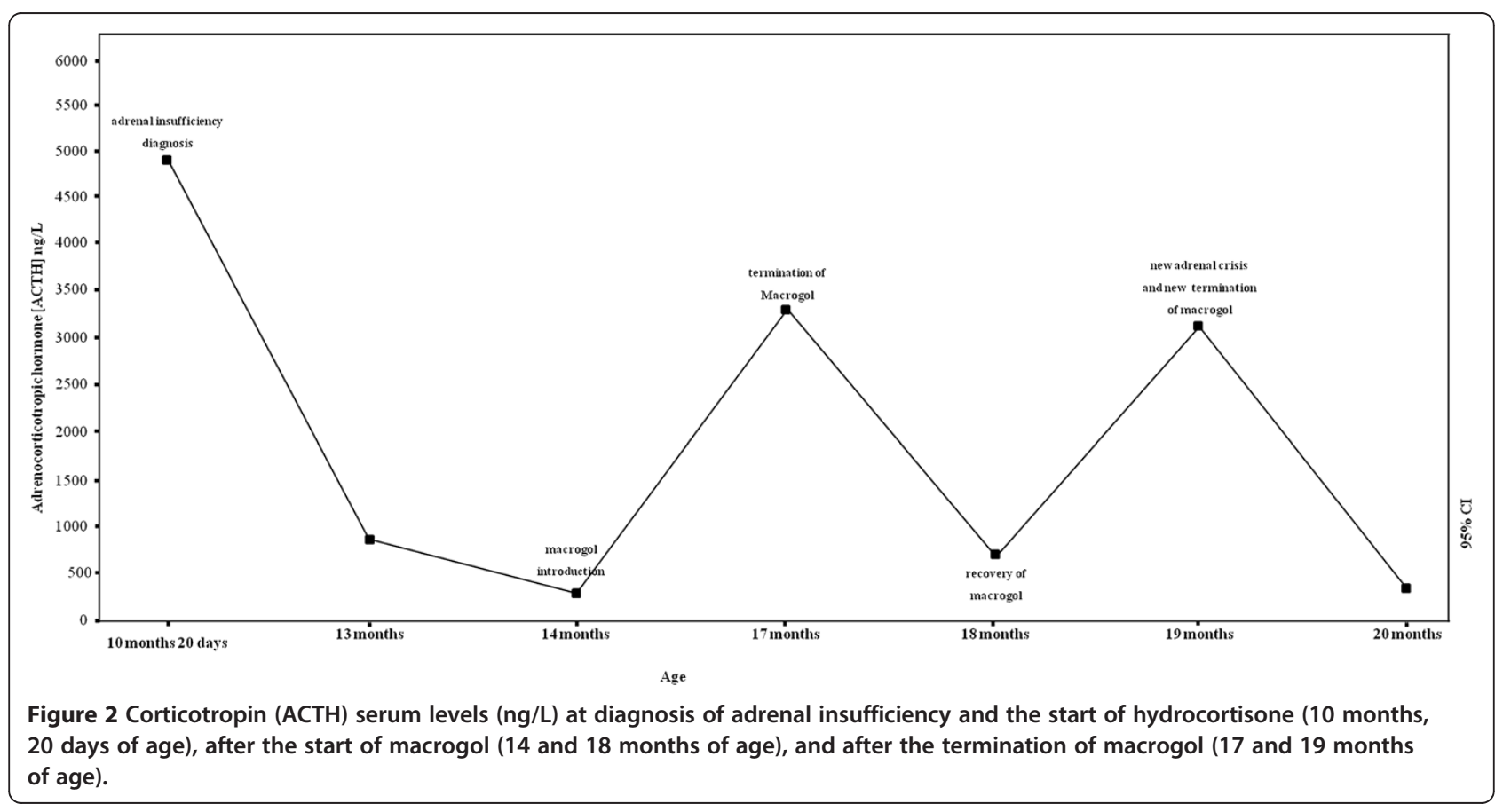


A drug's solubility in water is an important factor influencing its release into the body. In addition, macrogol softens the faecal mass by osmotically drawing water into the GI tract. As our case showed, it is possible that macrogol reduces the absorption of hydrocortisone, facilitating the appearance of adrenal insufficiency. The case seems to support our hypothesis, considering the significant changes in corticotropin after starting and stopping macrogol. Furthermore, we could also speculate that the introduction of macrogol close to that of hydrocortisone or fluorocortisone could cause or contribute to the reduced absorption of these drugs, triggering the adrenal crisis. In fact, it is recognised that many physiological gastrointestinal factors may strongly influence the plasma concentration-time profile of hydrocortisone [18]. However, hydrocortisone has a high permeability in both the small and large intestines, and the short elimination half-life (near $1.5 \mathrm{~h}$ ) requires two or more dose administrations per day [18].

This aspect is of great concern because patients with primary or secondary adrenal insufficiency have more than twofold increased mortality than the general population. However, recent data have demonstrated that the metabolic cardiovascular risk in hypopituitarism is related to the daily dose of hydrocortisone [15].

Our case report, while not demonstrating a genetic aetiology (polymorphism of SF1 was the only abnormality), gives evidence of a possible genetic primary cause of adrenal insufficiency, based on clinical and laboratory examinations and the age of onset. In children, congenital primary adrenal insufficiency is very rare, accounting for about $1 \%$ of all cases. The importance of elucidating a genetic basis is emphasised by the ever-increasing number of genetic causes of adrenal insufficiency (Table 1) [16]. In fact, in a series of 103 children with Addison's disease, genetic forms were very frequent, accounting for $72 \%$ of congenital adrenal hyperplasia; other genetic causes accounted for $6 \%$, whereas autoimmune disease was diagnosed in only $13 \%$ [19].

As stressed by this case, prompt diagnosis is also important because acute adrenal insufficiency is a life threatening disease. Typically, patients with this disease present with severe hypotension to hypovolaemic shock, vomiting, acute abdominal pain, and often fever. However, children often present with hypoglycaemia and hypoglycaemic seizures. On the other hand, the primary non-specific symptoms of chronic adrenal insufficiency in children are fatigue, reduced muscle strength, weight loss, anorexia, or failure to thrive [20].

\section{Conclusions}

This case report suggests that macrogol 3350 could interfere with the absorption of hydrocortisone. It is of particular importance considering the risk of adrenal insufficiency in these patients, and careful attention should be paid to the concomitant use of macrogol and hydrocortisone in subjects with primary or secondary glucocorticoid deficiencies.

\section{Consent}

Written informed consent was obtained from the parents of the patient for publication of this Case Report and any accompanying images.

\section{Competing interest \\ The authors declare that there are no conflicts of interest that could be perceived as prejudicing the impartiality of the research reported.}

\section{Authors' contributions}

SStagi: conception and design, endocrinological evaluation, manuscript writing and final approval of the manuscript. FR: data collection and analysis, manuscript writing and final approval of the manuscript. PDG: data collection and analysis, manuscript writing and final approval of the manuscript. Cl: endocrinological evaluation, data collection and analysis, manuscript writing and final approval of the manuscript. GP: data collection and analysis, critical revision and final approval of the manuscript. SSeminara: endocrinological evaluation, critical revision and final approval of the manuscript. MdM: critical revision and final approval of the manuscript. All authors read and approved the final manuscript.

\section{Acknowledgment}

We thank Prof. Paolo Lionetti for an invaluable help in revising our manuscript.

\section{Funding}

This research did not receive any specific grant from any funding agency in the public, commercial or not-for-profit sectors.

Received: 9 June 2014 Accepted: 4 September 2014

Published online: 26 September 2014

\section{References}

1. Shulman DI, Palmert MR, Kemp SF, Lawson Wilkins Drug and Therapeutics Committee: Adrenal insufficiency: still a cause of morbidity and death in childhood. Pediatrics 2007, 119:e484-e494.

2. Evliyaoğlu O, Dokurel İ, Bucak F, Özcabı B, Ercan Ö, Ceylaner S: Primary adrenal insufficiency caused by a novel mutation in DAX1 gene. J Clin Res Pediatr Endocrinol 2013, 5:55-57.

3. Charmandari E, Nicolaides NC, Chrousos GP: Adrenal insufficiency. Lancet 2014, pii:S0140-S6736.

4. Candy D, Belsey J: Macrogol (polyethylene glycol) laxatives in children with functional constipation and faecal impaction: a systematic review. Arch Dis Child 2009, 94:156-160.

5. Loening-Baucke $\mathrm{V}$ : Prevalence, symptoms and outcome of constipation in infants and toddlers. J Pediatr 2005, 146:359-363.

6. Sohy C, Vandenplus O, Sibille Y: Usefulness of oral macrogol challenge in anaphylaxis after intra-articular injection of corticosteroid preparation. Allergy 2008, 63:478-479.

7. Napke E, Stevens DGH: Excipients and additives: hidden hazards in drug products and in product substitution. CMAJ 1984, 131:1449-1452.

8. Bernier JJ, Donazzolo Y: Effect of low-dose polyethylene glycol 4000 on fecal consistency and dilution water in healthy subjects. Gastroentérol Clin Biol 1997, 21:7-11.

9. Schiller LR, Emmett M, Santa Ana CA, Fordtran JS: Osmotic effects of polyethylene glycol. Gastroenterology 1998, 94:933-941.

10. Hammer HF, Santa Ana CA, Schiller LR, Fordtran JS: Studies of osmotic diarrhea induced in normal subjects by ingestion of polyethylene glycol and lactulose. J Clin Invest 1989, 84:1056-1062.

11. Corazziari E: Need of the ideal drug for the treatment of chronic constipation. Ital J Gastroenterol Hepatol 1999, 31(Suppl 3):S232-S233.

12. Belsey JD, Geraint M, Dixon TA: Systematic review and meta analysis: polyethylene glycol in adults with non-organic constipation. Int J Clin Pract 2010, 64:944-955. 
13. Taylor RR, Guest JF: The cost-effectiveness of macrogol 3350 compared to lactulose in the treatment of adults suffering from chronic constipation in the UK. Aliment Pharmacol Ther 2010, 31:302-312.

14. Lee-Robichaud H, Thomas K, Morgan J, Nelson RL: Lactulose versus polyethylene glycol for chronic constipation. Cochrane Database Syst Rev 2010, 7, CD007570

15. Grossman A, Johannsson G, Quinkler M, Zelissen P: Therapy of endocrine disease: Perspectives on the management of adrenal insufficiency: clinical insights from across Europe. Eur J Endocrinol 2013, 169:T165-T175.

16. Charmandari E, Nicolaides NC, Chrousos GP: Adrenal insufficiency. The Lancet 2014, 383:2152-2167

17. Tooson JD, Gates LK Jr: Bowel preparation before colonoscopy. Choosing the best lavage regimen. Postgrad Med 1996, 100:203-214.

18. Lennernäs $H$, Skrtic S, Johannsson G: Replacement therapy of oral hydrocortisone in adrenal insufficiency: the influence of gastrointestinal factors. Expert Opin Drug Metab Toxicol 2008, 4:749-758.

19. Perry R, Kecha O, Paquette J, Huot C, Van Vliet G, Deal C: Primary adrenal insufficiency in children: twenty years experience at the Sainte-Justine Hospital, Montreal. J Clin Endocrinol Metab 2005, 90:3243-3250.

20. Avgerinos PC, Cutler GB Jr, Tsokos GC, Gold PW, Feuillan P, Gallucci WT, Pillemer SR, Loriaux DL, Chrousos GP: Dissociation between cortisol and adrenal androgen secretion in patients receiving alternate day prednisone therapy. J Clin Endocrinol Metab 1987, 65:24-29.

doi:10.1186/s13052-014-0078-2

Cite this article as: Stagi et al:: Hydrocortisone malabsorption due to polyethylene glycols (Macrogol 3350) in a girl with congenital adrenal insufficiency. Italian Journal of Pediatrics 2014 40:78.

\section{Submit your next manuscript to BioMed Central and take full advantage of:}

- Convenient online submission

- Thorough peer review

- No space constraints or color figure charges

- Immediate publication on acceptance

- Inclusion in PubMed, CAS, Scopus and Google Scholar

- Research which is freely available for redistribution 